\title{
RESENHA
}

COSTA, Ana Luiza Jesus da. O educar-se das classes populares no Rio de Janeiro oitocentista: escolarização e experiência. Jundiaí [SP]: Paco, 2019. 364p.; $21 \mathrm{~cm}$.

Simone Maria Magalhães Melean Universidade de São Paulo, Brasil Instituto Federal de São Paulo, Brasil magalhaessimone1623@gmail.com

\section{EDUCAÇÃO POPULAR E EDUCAÇÃO ESCOLAR SOB O OLHAR DE ANA LUIZA JESUS DA COSTA}

\section{Em O educar-se das classes populares no Rio de Janeiro oitocentista: escolarização e} experiência, Ana Luiza Jesus da Costa analisa diversas iniciativas populares de educação e de instrução organizadas por associações mutualistas e filantrópicas, presentes na sociedade fluminense da segunda metade do século XIX (COSTA, 2019, p. 18).

$\mathrm{Na}$ busca por compreender a apropriação da educação pelas classes populares, Ana Luiza estudou experiências educacionais num contexto definido por ela como o de "expansão do fenômeno associativo vivido pela sociedade oitocentista fluminense de forma ampla" ( $p$. 20). Desse contexto de expansão do associativismo Ana Luiza destacou cinquenta e duas associações de auxílio mútuo, beneficentes e da impressa operária, do período de 1835 a 1912, para entender como as classes populares se organizavam para criar espaços formativos, bem como identificar o sentido da educação e a participação das classes populares para incidir nas medidas políticas e sociais da educação naquele período (COSTA, 2019, p. 20).

Originário de sua tese de doutoramento ${ }^{1}$, o livro articula diversas fontes, organizadas pela autora em quatro grupos: a) associações de trabalhadores, tanto de auxílio mútuo e beneficência como as de resistência; b) periódicos da imprensa operária; c) abaixo-assinados de moradores e chefes de família requisitando ao Ministério do Império ou à Previdência da Província a abertura ou reabertura de escolas, códices sobre escolas subvencionadas e os relatórios dos presidentes da província do Rio de Janeiro; e, d) textos normativos como o Decreto $\mathrm{n}^{\mathrm{o}} 3029$ de 09 de janeiro de 1881, que trata da reforma eleitoral e, o Decreto $\mathrm{n}^{\circ} 8213$, de 13 de agosto de 1881 que implementa a Lei $n^{\circ} 3029$, que trata da legislação eleitoral (COSTA, 2019, p. 22).

\footnotetext{
${ }^{1} \mathrm{O}$ educar-se das classes populares no Rio de Janeiro oitocentista: escolarização e experiência, tese defendida por Ana Luiza Jesus da Costa, em 2012, na Faculdade de Educação da USP.
} 
Baseada nos estatutos das associações, relatórios de gestão, pareceres, legislação, artigos da imprensa dos trabalhadores, a autora vai tecendo sua narrativa, que procura esclarecer e demonstrar ao leitor e leitora a complexidade que envolve as experiências educacionais das classes populares do Rio de Janeiro na segunda metade do século XIX, desmistificando assim as análises que tendem a simplificar e homogeneizar o processo formativo da população pobre, negando-lhe protagonismo e resistência.

Interessada em descortinar os sentidos que a educação assumia para os sujeitos e suas múltiplas expressões engendradas pelas classes populares, Ana Luiza revela aspectos sociais e políticos importantes do Rio de Janeiro oitocentista que ajudam a compreender as disputas que envolviam o tema da educação naquele momento, e que colocava em movimento as forças do poder privado, o Estado imperial e as classes populares (p. 31). Nesse sentido, a autora recupera o debate acerca da exclusão dos analfabetos da política oficial, ao mesmo tempo que as elites iam sedimentando o "mito" da alfabetização como critério balizador da participação política e de cidadania (p. 28). Nesse contexto, a reforma eleitoral de 1881 foi decisiva para consolidar a concepção elitista do analfabetismo como critério para a exclusão social e política (p. 74).

Ana Luiza localiza nas últimas décadas do século XIX a emergência do "mito" da alfabetização como requisito de civilidade e condição para assegurar a participação política pelo voto, mas desconfia da narrativa que se ampara na taxa de analfabetismo informada pelos censos de 1872 e 1890 , os quais indicavam existir $82,5 \%$ de analfabetos na população do Rio de Janeiro (p. 39).

Ao se perguntar: "será mesmo que o que se supunha 'o povo analfabeto' do Rio de Janeiro estava tão alheio à política e à própria educação?” (p. 28), Ana Luiza acaba por interrogar também os critérios quantitativos como os únicos legítimos e capazes de informar sobre a complexidade social, educacional e de discernimento da sociedade fluminense oitocentista (p. 28-29). Sociedade que passava a consolidar a concepção segundo a qual a escolarização era entendida como "um importante critério de socialização" (p. 31) critério esse amparado por um "discurso governamental que atribuía a si o direito de formar os cidadãos" (p. 31). Não obstante, na prática, esse discurso oficial não se realizava, já que a instrução primária de adultos e crianças pobres era promovida por iniciativas particulares ou de associados. Portanto, mediante uma relação conflituosa com o Estado, as classes populares tomavam para si a luta pela escolarização, realizando "ações diretas, coletivas ou individuais", que passavam por organizar escolas ou até realizar investimentos para garantir a frequência às aulas oferecidas pelo Estado ou por entidades sociais (p. 31- 32). 
Ao assinalar os significados da educação para as classes populares oitocentista, a autora informa que ao lado das reivindicações por educação escolar estatal havia diversas iniciativas da sociedade civil, incluindo aquelas ligadas ao movimento operário organizado, que compunham o amplo espectro de iniciativas do educar-se das classes populares (p. 37). Trazendo para sua análise, por exemplo, algumas passagens de crônicas do escritor carioca João do Rio, Ana Luiza identifica reflexões, saberes e conhecimentos entre cocheiros, estivadores, marinheiros, construtores de presépios, leitores e pintores em seus momentos de trabalho e lazer, com os quais se indica o uso popular da escrita e sua presença na arena pública, no caso, nas ruas (p. 38-39).

Ao analisar a atividade dos tatuadores, arte praticada por trabalhadores pauperizados, Ana Luiza destaca uma cena em que o tatuador demonstra saber escrever já que deveria tatuar o nome na pele de um cliente. Assim, ela salienta existir flagrante contradição entre as estatísticas que apontavam a elevada taxa de analfabetismo e a realidade em que se observa, por outras fontes, o uso popular da escrita (p. 39).

Ao afirmar que a educação não se restringia à escola, assim como a forma de atuação política praticada pelas classes populares não se vinculava ao parlamento e ao voto, Ana Luiza adverte que a concepção que idealiza a participação política somente como aquela que se relaciona institucionalmente com o Estado por meio do voto - uma visão meramente institucionalista - pode deixar de fora o conjunto de ações praticadas pelas classes populares tão necessárias para a sua sobrevivência e existência social, bem como para a exigência do direito à educação. Por isso, a autora realiza o exercício de compreender a história a partir das experiências e dos fazeres das classes populares, na perspectiva de estruturar sua narrativa a partir dos "de baixo" (p. 40).

Interessada em narrar a partir da perspectiva dos "de baixo", mas sem perder de foco o poder das elites para submeter e manter a sua hegemonia, a autora demonstra, por exemplo, que a Lei Saraiva, ao instituir a separação entre instrução e experiência, se constituiu em importante mecanismo de interdição dos direitos políticos do povo negro, pois proibia a criação de organizações de trabalhadores negros para evitar que se alfabetizassem (p. 64). Vigiar a atuação dos negros para impedir sua organização e resistência ao sistema escravocrata e colonial era uma prática constante das elites, como salientou a autora na passagem em que discute o Ofício de 27 de março de 1835, no qual Euzébio de Queirós solicita vigilância policial sobre as reuniões para coibir o aprender a ler e escrever dos "pretos minas" (p. 36). Sabe-se, contudo, que as elites não apenas operavam a estrutura de poder para impedir que os negros fossem sujeitos de direitos, mas, sobretudo, que acessassem o principal meio de produção para a 
garantia de trabalho e subsistência: a terra. Sem direito à propriedade da terra, sem acesso aos meios de produção, os negros seguiam encontrando muitos obstáculos para acessar direitos sociais e políticos.

A análise de Ana Luiza também discute a função do mito do analfabetismo e como ele operava institucionalmente na sociedade fluminense oitocentista com a finalidade de deixar de fora da cena pública e política o povo em favor de um determinado extrato social. Isto é, sob a justificativa do analfabetismo, o governo imperial justificava a sua perseguição e proibição à organização dos trabalhadores negros. Ademais, a autora afirma ser este o mito fundador que origina os nossos sistemas político e educacional (p. 64-75) que continuam a naturalizar e a perpetuar os processos de exclusão e desigualdade, a despeito das lutas e resistências históricas.

Ao caracterizar as cinquenta e duas associações escolhidas para o estudo, Ana Luiza demonstra que elas atuavam para enfrentar coletivamente a pobreza - parte da realidade social dos trabalhadores - e ao fazê-lo, colocava em curso processos formativos significativos e estratégicos para os sujeitos. As práticas formativas e educativas desenvolvidas nas associações contribuiriam para a formação intelectual e política dos trabalhadores e, conforme sugere a autora, ajudaram a sedimentar a transformação de experiências ao enfretamento da pobreza em ações e lutas por direitos; sustenta que as práticas de auxílio mútuo e as redes de solidariedade dos trabalhadores, a participação ativa das classes populares nos processos de educação e instrução são balizadoras para a mudança de uma concepção que tinha a educação como dádiva, caridade, para a concepção da educação como direito (p. 108-109).

Nesse contexto, destaca-se a centralidade que assumiam os estatutos para a organização das associações, pois continham o "caráter legislativo, formalizado e formalizador", contribuindo para a garantia da sua existência legal (p. 113). Respeitado como "lei máxima das entidades", o estatuto possuía função organizativa, que, conforme a análise da autora, indicava a familiaridade e a existência de práticas de leitura, escrita e cálculo, já que era dever de cada membro ter conhecimento e observar os relatórios, as atas, leis escritas e balanços de sua entidade. Ademais, sustenta a autora que, seja na direção da entidade ou mesmo na assembleia geral, os membros necessitavam discutir, deliberar, aprovar ou rejeitar reformas do estatuto, bem como elaborar seu raciocínio e expressá-lo publicamente, e, dessa maneira, desenvolviam habilidades que exigiam intensa ação reflexiva. Portanto, salienta a autora que "a fonte e o momento dos estudos era a própria vida da entidade, a própria experiência dos sócios" (p. 174175).

O estudo de Ana Luiza destaca ainda que as associações atuantes no período entre 1870 e 1890 e 1890 e 1917 ofertavam cursos, conferências, organizavam bibliotecas, jornais e 
fundavam escolas para os filhos de seus associados, demonstrando a valorização da cultura letrada e da instrução (p. 184). Enquanto as fontes oficiais revelam que o modelo reconhecido e adotado pelo Estado pretendia governar a infância e civilizar a classe trabalhadora, as fontes primárias - relatórios, estatutos, atas das associações - revelam que as classes populares eram criadoras e criaturas de processos próprios de ensino e aprendizado. (p. 188-198). Evidencia-se assim que um estudo que se vale apenas de fontes previsíveis e institucionalizadas, tende unicamente a reproduzir e naturalizar aspectos da realidade que interessam a manutenção do status quo.

A classe trabalhadora, organizada, participava ativamente das disputas em torno da educação, explicitando publicamente seus posicionamentos em defesa da instrução formal. Por meio de seus periódicos defendiam a instrução como uma forma para a melhoria da condição social e como dimensão humanizadora. Ana Luiza aponta que a imprensa operária concebia a instrução "como direito a ser adquirido e, ao mesmo tempo, condição para exercício de direitos" (p. 262).

Não obstante a Reforma de 1879 ter tornado o ensino obrigatório, a educação escolar permanecia restrita a poucos e a sua oferta à população não acontecia satisfatoriamente e nem regularmente, visto que o governo Imperial não assegurava o financiamento estatal para o suprimento da escolarização pública. Os parcos recursos destinados à escola pública privilegiavam aquelas unidades das áreas urbanas; para o meio rural e áreas menos populosas, onde residia parte da população pobre, os governos das províncias adotaram a escola subvencionada, um modelo que dependia do repasse de verba governamental para subsidiar a iniciativa de professores individuais ou de pais e moradores das localidades rurais para a oferta de curso de instrução primária² .

O investimento para a subvenção de vagas era muito inferior ao destinado para a escola pública dos centros urbanos. Como mostra Ana Luiza, era muito comum reclamações sobre o atraso e irregularidade no pagamento das subvenções, além dos valores serem insuficientes para arcar com o aluguel, material didático e sustento do professor (p. 292). A subvenção, contudo, era uma estratégia adotada pelos governos das províncias para economizar recursos destinados à instrução pública das crianças pobres, e que fez emergir, sob critério econômico, um modelo educacional dual que aportava melhor investimento conforme o público e a região (p. 299).

\footnotetext{
${ }^{2}$ Cumpre ressaltar que algumas províncias estavam passando pela aceleração da transformação de uma economia agro-exportadora-escravista para uma economia urbano-comercial.
} 
No Rio de Janeiro oitocentista, as classes populares eram excluídas da participação política por não possuir escolarização e o Estado se isentava da oferta universal e obrigatória da instrução, atuando conforme sua ordem de interesse e controle.

A esse respeito, é importante salientar que, atualmente, as classes populares no Brasil contam com a obrigatoriedade e a universalidade da educação básica, mas continuam a enfrentar desafios históricos para a efetivação da Educação como Direito a ser garantido pelo Estado. Vale lembrar que assentados da reforma agrária, indígenas, quilombolas, acampados, caiçaras, povos das florestas, ribeirinhos, enfim, populações do campo brasileiro, mesmo fazendo lutas e resistências, tiveram aproximadamente 80 mil escolas fechadas em seus territórios entre 1997 e 2018, conforme denunciam os professores Paulo Alentejano e Tássia Cordeiro, com base nos dados do censo escolar do INEP. ${ }^{3}$ Como apontam os professores, foram fechadas 4 mil escolas do campo por ano, o que contribui sensivelmente para aprofundar a desigualdade dos níveis de escolaridade entre pessoas das áreas rurais e urbanas no país.

Desde a reprodução da desigualdade, que se estrutura num sistema educacional que opõe as redes públicas e privadas, passando pela sistemática precarização das instalações e infraestrutura das escolas públicas e das relações de trabalho na educação, as classes populares enfrentam contemporaneamente projetos que visam subordinar as práticas pedagógicas ao modelo de treinamentos para alcançar habilidades e competências capazes de domesticar os estudantes e reduzir os seus horizontes à mera formação de mão-de-obra a ser disponibilizada no mercado de trabalho. Para convencer as filhas e filhos das/dos trabalhadores sobre esse modelo de instrução, a lógica empresarial neoliberal operada, por exemplo, por meio de parcerias público-privadas, atua na oferta de um currículo educacional reduzido, esvaziado e aligeirado, que substitui disciplinas e conhecimentos científicos, em favor de temas como "projeto de vida", competências "socioemocionais" e "empreendedorismo", sugerindo aos estudantes a escolha de seus "itinerários formativos". Na prática, porém, as diretrizes de sua formação já foram previamente definidas sem a participação das comunidades escolares e acadêmicas nem das classes populares como se verifica no processo de implementação do Novo Currículo do Ensino Médio por meio da Lei nº 13.415/2017, alinhando à Base Nacional Comum Curricular (BNCC).

\footnotetext{
${ }^{3}$ Paulo Alentejano é professor do Departamento de Geografia da Universidade Estadual do Rio de Janeiro (UERJ) e Tássia Cordeiro é professora do Instituto Federal Fluminense e doutoranda do Programa de Políticas Públicas e Formação Humana da UERJ. ALENTEJANO, P.; CORDEIRO, T. 80 mil escolas no campo foram fechadas em 21 anos. IN: Jornal Brasil de Fato, São Paulo, 29 de novembro de 2019. Disponível em: https://www.brasildefato.com.br/2019/11/29/artigo-or-80-mil-escolas-no-campo-brasileiro-foram-fechadas-em21-anos. Acesso em: 24 nov. 2021.
} 
No entanto, como mostra Ana Luiza em seu estudo, quando as classes populares se colocam em movimento, elas se constituem numa força capaz de desnudar as contradições do projeto educacional levado a cabo pelo Estado burguês que oblitera a efetivação da Educação como direito humano fundamental em favor da sua mercantilização.

Recebido em: 13 de dezembro de 2021

Aceito em: 14 de dezembro de 2021 